\title{
An Empirical Survey on the Influence of Machining Parameters on Tool Wear in Diamond Turning of Large Single Crystal Silicon Optics
}

\author{
D. Krulewich, C. Syn \\ P. Davis, M. Zimmermann \\ K. Blaedel, J. Carr \\ J. Haack, M.R. McClellan \\ W.A. Goodman \\ This paper was prepared for submittal to the \\ American Society for Precision Engineering \\ 14th Annual Meeting \\ Monterey, CA \\ October 31-November 5, 1999
}

July 1999

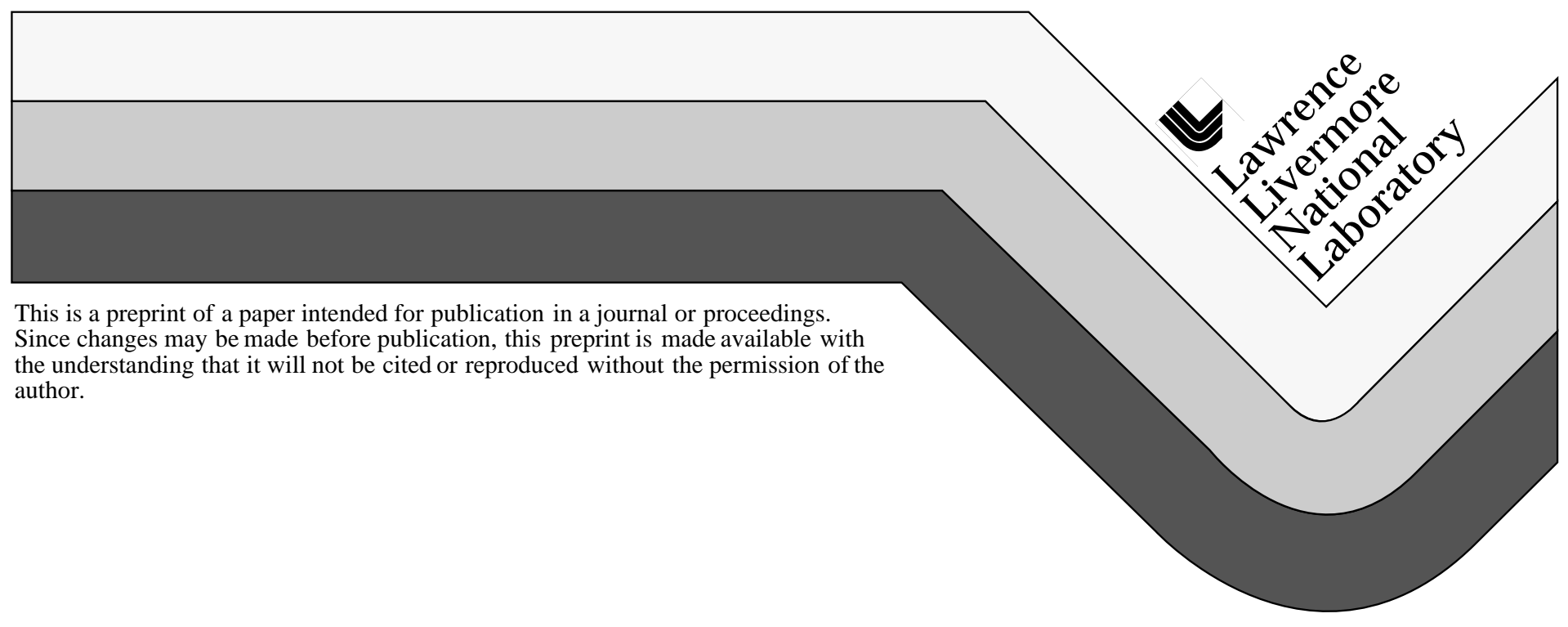




\section{DISCLAIMER}

This document was prepared as an account of work sponsored by an agency of the United States Government. Neither the United States Government nor the University of California nor any of their employees, makes any warranty, express or implied, or assumes any legal liability or responsibility for the accuracy, completeness, or usefulness of any information, apparatus, product, or process

disclosed, or represents that its use would not infringe privately owned rights. Reference herein to any specific commercial product, process, or service by trade name, trademark, manufacturer, or otherwise, does not necessarily constitute or imply its endorsement, recommendation, or favoring by the United States Government or the University of California. The views and opinions of authors expressed herein do not necessarily state or reflect those of the United States Government or the University of California, and shall not be used for advertising or product endorsement purposes. 


\title{
An Empirical Survey on the Influence of Machining Parameters on Tool Wear in Diamond Turning of Large Single Crystal Silicon Optics
}

\author{
D. Krulewich, C. Syn, P. Davis, M. Zimmermann, K. Blaedel, J. Carr, J. Haack \\ Lawrence Livermore National Laboratory, Livermore CA 94551 \\ M. R. McClellan, Schafer Corp., Livermore CA 94550 \\ W. A. Goodman, Schafer Corp., Calabasas CA 91302
}

\section{INTRODUCTION}

The research described in this paper is a continuation of the collaborative efforts by Lawrence Livermore National Laboratory (LLNL), Schafer Corporation and TRW to develop a process for single point diamond turning (SPDT) of large single crystal silicon (SCSi) optical substrates on the Large Optic Diamond Turning Machine (LODTM). The principal challenge to obtaining long track lengths in SCSi has been to identify a set of machining parameters which yield a process that provides both low and predictable tool wear. Identifying such a process for SCSi has proven to be a formidable task because multiple crystallographic orientations with a range of hardness values are encountered when machining conical and annular optical substrates. The LODTM cutting program can compensate for tool wear if it is predictable. However, if the tool wear is not predictable then the figured area of the optical substrate may have unacceptably high error that can not be removed by post-polishing. The emphasis of this survey was limited to elucidating the influence of cutting parameters on the tool wear. We present two preliminary models that can be used to predict tool wear over the parameter space investigated.

During the past two and one-half years a series of three evolutionary investigations were performed. The first investigation, the Parameter Assessment Study (PAS), was designed to survey fundamental machining parameters and assess their influence on tool wear [1]. The results of the PAS were used as a point-of-departure for designing the second investigation, the Parameter Selection Study (PSS). The goal of the PSS was to explore the trends identified in the PAS in more detail, to determine if the experimental results obtained in the PAS could be repeated on a different diamond turning machine (DTM), and to select a more optimal set of machining parameters that could be used in subsequent investigations such as the Fluid Down-Select Study (FDS). The goal of the FDS was to compare the performance of water, polyalkaline glycol and HT200 as a cutting fluid for SCSi, and select a single baseline cutting fluid from this set for use in future SCSi SPDT efforts. Synopses of the experimental work and results of the PAS and PSS are now presented.

\section{PARAMETER ASSESSMENT STUDY AND RESULTS}

The cutting parameters surveyed during the PAS included depth of cut, surface velocity, feed rate, tool nose radius, rake angle and side rake angle, machined area and cutting fluid. The range of cutting parameters was selected to achieve material removal via the ductile mode [2-4]. Experimental design techniques were used to reduce the full factorial set of experiments to a reduced set of fourteen machining experiments, shown in Table $1[1,5]$. Multiple parameters were varied in each experiment, which allowed optimum statistical analysis of the data.

The PAS was performed on the LLNL DTM II. DTM II is a precision lathe with a horizontal air bearing spindle and rolling element axes. Each experiment used a freshly sharpened diamond tool to cut a $25.4 \mathrm{~mm}$ wide track around an initially damage-free $143.5 \mathrm{~mm}$ diameter by $254 \mathrm{~mm}$ long (100) SCSi boule. Seven experimental tracks were cut prior to restoring the boule to a damage-free condition and completing the last 7 experiments.

Figure 1 shows the tool geometry used. The clearance angle was $7^{\circ}$ for all tools. The tool nose profile was measured before and after each experiment by rotating an air bearing linear variable differential transformer (LVDT) probe around the nose of the tool. An example tool trace is shown in Figure 2. The x-axis shows the position along the tool radius in degrees while the y-axis shows the measured tool profile. The tool nose recession (wear) was calculated by taking the difference between the before and after tool nose profiles. Tool wear volume was obtained by integrating the profile between the wear land on the clearance face and the initial tool surface. The wear pattern was observed using both optical and scanning electron microscopes. Figure 3 shows a SEM photograph of the tool wear. The rake face has developed a typical chip crater. Although the chip crater may eventually cause catastrophic failure of the tool, we are more concerned with the wear flat between the rake face and clearance face. This wear flat will produce unacceptable figure error in the part prior to tool failure.

The PAS was very successful in identifying machining parameter influences on tool wear. Since each parameter had a low and high value only simple, linear trends were made. Analysis of the Table 1 data indicated that low tool wear was attainable if: 1) the feed rate was high, 2) the depth of cut was low, 3) the cutting velocity was high, 4) the rake angle was negative, 5) the side rake angle was zero degrees and 6) the tool radius was large. Additionally, photomicroscopy of the boule after cutting clearly showed that additions of water and tri-potassium phosphate to 
PAG produced poor surface finish. Consequently, these cutting fluids were discarded. It was also discovered that PAG acted as a solvent on some fluid supply tubing and painted surfaces of the DTM.

\section{PARAMETER SELECTION STUDY AND RESULTS}

The PSS was performed on the LLNL Phoenix DTM due to unavailability of DTM. The Phoenix DTM, shown in Figure 4, is a precision lathe with a horizontal air bearing spindle and rolling element axes, and the same spindle design as the DTM II. The Phoenix DTM was outfitted with PAG compatible Tygon tubing prior to performing the experiments.

The PSS utilized the same experimental design techniques used in the PAS. Seven new experiments were designed and two PAS experiments (\#1 and \#2) were duplicated to confirm machine-to-machine repeatability. The new experiments explored the effects of increased feed rate, increased tool radius, increased negative rake angle, increased cutting area, decreased surface velocity, and eliminated side rake angle while retaining the same values for depth of cut. Again, freshly sharpened tools were used to cut the refurbished PAS SCSi boule. A single $25.4 \mathrm{~mm}$ wide track and three $50.8 \mathrm{~mm}$ wide tracks were cut prior to restoring the boule to a damage-free condition and completing the remaining experiments.

The experiments and results of the PSS are presented in Table 2. The duplicated PAS experiments showed that the SPDT of SCSi is repeatable over time and on different machines. A description of the tool wear models that were developed is required to discuss the influence of machining parameters on the tool wear. Two separate, yet similar, models were developed: the LLNL Tool Wear model is an extension of the Taylor Tool Life Equation, and the Goodman Tool Wear algorithm is an extension of the uncut chip thickness relationship.

\section{MODEL DEVELOPMENT}

The LLNL Tool Wear model departs from the expanded version of the Taylor Tool Life Equation that relates tool lifetime (T) to feed rate (f), depth of cut (doc), velocity (V) and a tool geometry constant (K) [6].

$$
\mathrm{T}=\frac{\mathrm{K}}{\mathrm{V}^{1} / \mathrm{f}^{1 / 1} \mathrm{doc}^{1} / 2}
$$

Equation (1) assumes that cutting speeds are high enough to ignore edge effects. Since this study uses relatively low speeds, the exponential relationship for velocity is not appropriate. Therefore, a quadratic expression that does not force tool wear to monotonically increase as velocity increases was used. During this study the tool geometry, machine and cutting fluid were varied. Therefore, $\mathrm{K}$ in Equation (1) is a function of tool geometry, machine and cutting fluid rather than a constant. Tool wear as a function of tool rake angle was incorporated using a quadratic equation to define regions of high and low tool wear. Side rake angle was excluded from the model because data analysis showed little correlation with tool wear. Cutting time (area/velocity/feed rate) was allowed an exponential relation with tool life due to the relatively short track lengths of the experiments. Based on these premises, the LLNL Tool Wear Model is:

$$
\mathrm{W}=\left(\mathrm{K}_{\text {fluid }}+\mathrm{K}_{\text {machine }}+\mathrm{b}_{1} \alpha^{2}+\mathrm{b}_{2} \alpha\right)\left(\mathrm{V}^{2}+\mathrm{b}_{3} \mathrm{~V}\right) \mathrm{f}^{\mathrm{b} 4} \mathrm{doc}^{\mathrm{b} 5} \mathrm{Area}^{\mathrm{b} 6}
$$

where $\mathrm{K}_{\text {fluid }}$ is a unique constant for each of the three cutting fluids, $\mathrm{K}_{\text {machine }}$ is a unique constant for each of the two machines, $\alpha$ is negative rake angle, and Area is the machined area. The constants $b_{1}-b_{6}$ are determined from the experimental data. Equation (2) was fit to the experimental data in Tables 1 and 2 using a non-linear least squares algorithm. Exercising the equation provided the following results:

(1) For a given area, tool wear was minimized when the feed rate was as high as possible,

(2) Smaller depths of cut showed less tool wear for the range tested (from 40 to $200 \mu \mathrm{in}$ ),

(3) Optimum rake angle was approximately $-30^{\circ}$ within the range tested (from $-60^{\circ}$ to $0^{\circ}$ ),

(4) The worst surface velocity is approximately $350 \mathrm{ft} / \mathrm{min}$. Tool wear improves at either higher or lower surface velocities for the range tested (from 100 to $750 \mathrm{ft} / \mathrm{min}$ ),

(5) Tool radius within the range tested (from 0.03" to 0.2") was not of great influence, and

(6) Side rake angle of the tool had no effect

The Goodman Tool Wear algorithm, Equation (3), includes terms for the uncut chip relation, the tool radius $(\mathrm{r})$, the machined area, rake angle $(\alpha)$, skew angle $(\beta)$ and work energy. The constants $\mathrm{x} 1$-x6 were found using Schafer's proprietary non-linear optimization program to fit the data. Table 3 shows that the calculated tool wear is in excellent agreement with the actual tool wear. Equation (3) favors a high negative rake angle, no skew and a large tool nose radius, but otherwise agrees with the LLNL Tool Wear Model predictions.

$$
\mathrm{W}=(\mathrm{x} 1)\left[(\mathrm{f})^{\mathrm{x} 2}\left(\mathrm{doc} / \mathrm{r}^{2}\right)^{\mathrm{x} 3}\right](\text { Area })^{\mathrm{x} 4}(1 / \sin \alpha)^{\mathrm{x} 5}(\sin \beta)^{\mathrm{x} 6}(\mathrm{~V})^{\mathrm{x} 7}
$$


Table 1. PAS Experimental Matrix and Resultant Tool Wear

\begin{tabular}{|c|c|c|c|c|c|c|c|c|c|}
\hline $\begin{array}{c}\operatorname{Exp} \\
\# .\end{array}$ & $\begin{array}{l}\text { Surface } \\
\text { Velocity } \\
\text { (ft/min) }\end{array}$ & 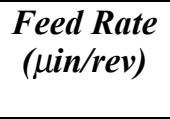 & $\begin{array}{c}\text { Depth of } \\
\text { Cut } \\
(\mu i n)\end{array}$ & $\begin{array}{c}\text { Tool } \\
\text { Radius } \\
\text { (in) }\end{array}$ & $\begin{array}{c}\text { Rake } \\
\text { Angle } \\
\text { (degrees) }\end{array}$ & $\begin{array}{c}\text { Side rake } \\
\text { Angle } \\
\text { (degrees) }\end{array}$ & $\begin{array}{l}\text { Area } \\
\left(\mathrm{in}^{2}\right)\end{array}$ & $\begin{array}{l}\text { Cutting } \\
\text { Fluid* }\end{array}$ & $\begin{array}{l}\text { Tool } \\
\text { Wear } \\
\text { (uin) }\end{array}$ \\
\hline 1 & 750 & 50 & 200 & 0.06 & 0 & 0 & 15.7 & 1 & 25.2 \\
\hline 2 & 100 & 120 & 200 & 0.06 & -40 & 0 & 15.7 & 1 & 6.8 \\
\hline 3 & 100 & 120 & 40 & 0.03 & 0 & 40 & 15.7 & 1 & 19.5 \\
\hline 4 & 750 & 50 & 40 & 0.06 & 0 & 40 & 15.7 & 1 & 12.7 \\
\hline 5 & 100 & 50 & 40 & 0.03 & -40 & 40 & 15.7 & 1 & 23.9 \\
\hline 6 & 100 & 120 & 200 & 0.03 & 0 & 0 & 15.7 & 2 & 9.2 \\
\hline 7 & 750 & 120 & 40 & 0.03 & -40 & 0 & 15.7 & 2 & 2.6 \\
\hline 8 & 100 & 50 & 40 & 0.03 & 0 & 40 & 15.7 & 2 & 30.5 \\
\hline 9 & 750 & 120 & 200 & 0.06 & 0 & 40 & 15.7 & 2 & 5.5 \\
\hline 10 & 100 & 50 & 200 & 0.06 & -40 & 40 & 15.7 & 2 & 5.2 \\
\hline 11 & 750 & 50 & 200 & 0.03 & 0 & 0 & 15.7 & 3 & 17.4 \\
\hline 12 & 100 & 50 & 40 & 0.06 & -40 & 0 & 15.7 & 3 & 20.3 \\
\hline 13 & 100 & 120 & 40 & 0.06 & 0 & 40 & 15.7 & 3 & 16.9 \\
\hline 14 & 750 & 120 & 200 & 0.03 & -40 & 40 & 15.7 & 3 & 4.4 \\
\hline
\end{tabular}

* Fluid 1=PAG; Fluid 2=PAG with water; Fluid 3=PAG with water and tri-potassium phosphate

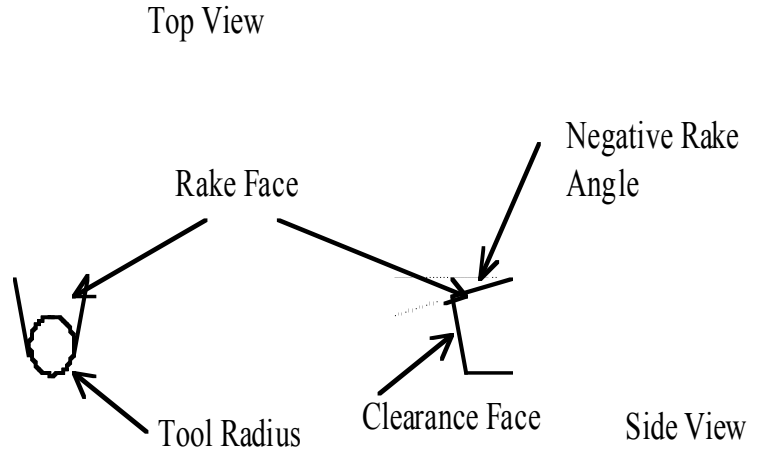

Figure 1. Tool Geometry

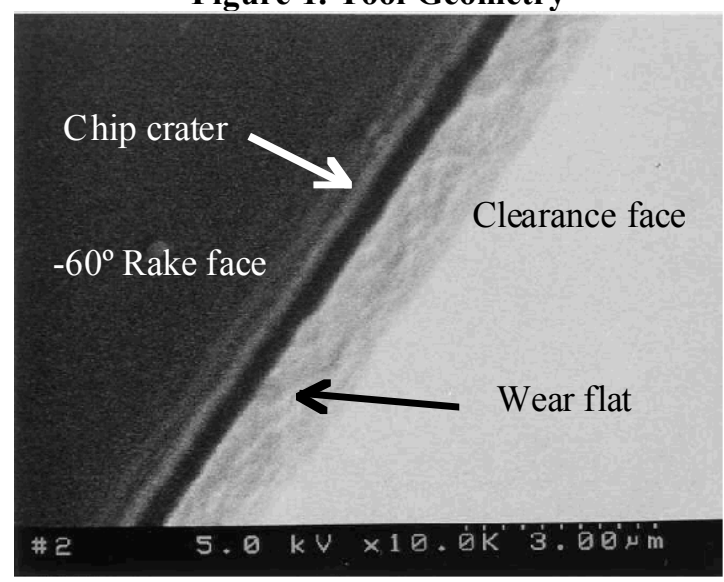
FDS

Figure 3. SEM Photograph of Tool Wear

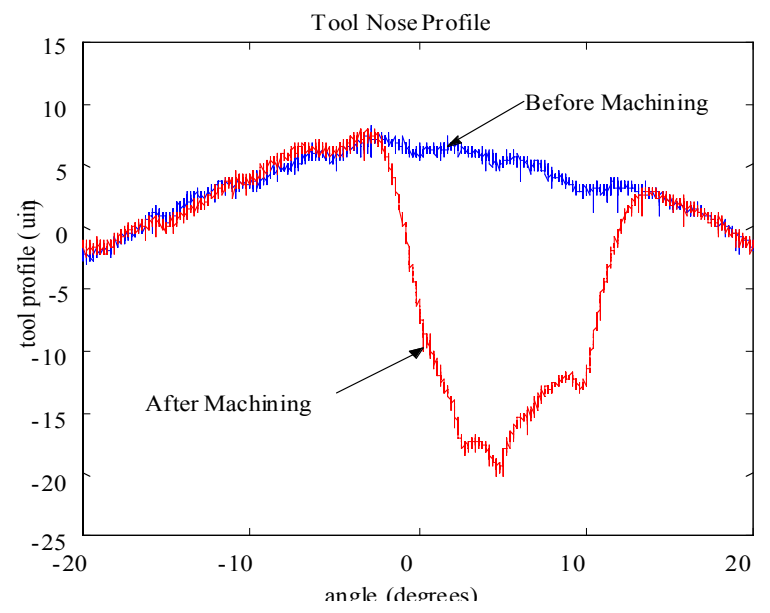

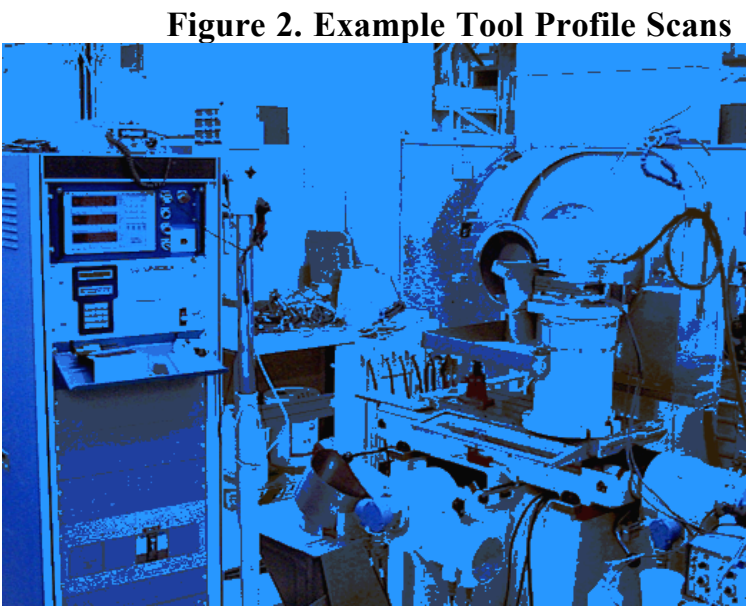

Figure 4. Phoenix DTM Used for PSS and

Table 2. PSS Experimental Matrix and Resultant Tool Wear 


\begin{tabular}{cccccccc}
\hline Exp\#. & $\begin{array}{c}\text { Velocity } \\
(\boldsymbol{f t / m i n})\end{array}$ & $\begin{array}{c}\text { Feed Rate } \\
(\mu \mathrm{in} / \text { rev })\end{array}$ & $\begin{array}{c}\text { DOC } \\
(\mu \text { Tin })\end{array}$ & $\begin{array}{c}\text { Tool Radius } \\
(\text { in })\end{array}$ & $\begin{array}{c}\text { Rake Angle } \\
(\text { degrees })\end{array}$ & $\begin{array}{c}\text { Area } \\
\left(\text { (in }^{2}\right)\end{array}$ & $\begin{array}{c}\text { Tool Wear } \\
(\mu \text { in })\end{array}$ \\
\hline Repeat of PAS \#2 & 100 & 120 & 200 & 0.06 & -40 & 15.7 & 7.0 \\
1 & 100 & 50 & 200 & 0.06 & -60 & 31.4 & 25.0 \\
2 & 100 & 250 & 200 & 0.20 & 0 & 31.4 & 0.9 \\
3 & 600 & 50 & 200 & 0.06 & 0 & 31.4 & 35.0 \\
4 & 600 & 250 & 40 & 0.06 & 0 & 15.7 & 2.0 \\
5 & 600 & 250 & 40 & 0.20 & -60 & 31.4 & 2.75 \\
6 & 100 & 250 & 200 & 0.20 & 0 & 31.4 & 1.0 \\
7 & $\mathbf{1 0 0}$ & $\mathbf{2 5 0}$ & $\mathbf{4 0}$ & $\mathbf{0 . 2 0}$ & $\mathbf{- 6 0}$ & $\mathbf{3 1 . 4}$ & $\mathbf{5 . 0}$ \\
Repeat of PAS \#1 & $\mathbf{7 5 0}$ & 50 & 200 & 0.06 & 0 & 15.7 & 31.0 \\
\hline
\end{tabular}

PSS Experiment 7 Baselined for FDS Experiments

Table 3. Goodman Tool Wear Algorithm Results

\begin{tabular}{ccc}
\hline Experiment & Tool Wear $(\mu$ in) & Calculated Tool Wear $(\mu$ in $)$ \\
\hline PAS \#1 & 25.2 & 28.1 \\
PAS \#2 & 6.8 & 7.1 \\
PAS \#3 & 19.5 & 19.3 \\
PAS \#4 & 12.7 & 12.7 \\
PAS \#5 & 23.9 & 24.1 \\
Repeat of PAS \#2 & 7.0 & 7.1 \\
PSS \#1 & 25.0 & 24.8 \\
PSS \#2 & 0.9 & 1.83 \\
PSS \#3 & 35.0 & 35.1 \\
PSS \#4 & 2.0 & 1.33 \\
PSS \#5 & 2.75 & 0.13 \\
PSS \#6 & 1.0 & 1.83 \\
PSS \#7 & 5.0 & 0.25 \\
Repeat of PAS \#1 & 31.0 & 28.1 \\
\hline
\end{tabular}

1. C.K. Syn, D.A. Krulewich, P.J. Davis, M.R. McClellan, P.C. DuPuy, M.A. Wall, and K.L. Blaelel, "An Empirical Survey on the Influence of Machining Parameters in Diamond Turning of Large Single Crystal Silicon Optics", ASPE Spring Topical Meeting on Silicon Machining Proceedings, 1998, 17, 44-49

2. P. N. Blake and R. O. Scattergood, "Ductile-regime machining of germanium and silicon", Journal of the American Ceramic Society, 1990, 73 (4), 949-957.

3. C. K.Syn, J. S. Taylor, R. R. Donaldson, and S. Shimada, Proc. JSPE 1988 Spring Meeting, Kawasaki, Japan, pp. 781-782.

4. W. S. Blackley and R. O. Scattergood, "Ductile-regime machining model for diamond turning of brittle materials", Precision Engineering, 1991,13 (2), 95-103.

5. D.A. Krulewich, "Experimental design for single point diamond turning of silicon optics", UCRL-ID-127385, (1996)

6. E.J.A. Armarego and R.H. Brown, The Machining of Metals, Prentice-Hall, Inc., N.J. (1969)

This work was performed under the auspices of the USDOE by LLNL under contract No. W-7405-Eng-48. 